\title{
Investigations of Electrical Trees in the Inner Layer of XLPE Cable Insulation Using Computer-aided Image Recording Monitoring
}

\author{
Ansheng $\mathrm{Xie}^{1,2}$ \\ ${ }^{1}$ State Key Laboratory of Electrical Insulation and Power Equipment \\ Xi'an Jiaotong University, Xi'an, Shaanxi, 710049, China \\ ${ }^{2}$ School of Environment Science and Engineering \\ Chang'an University, Xi'an, Shaanxi, 710054, China \\ Xiaoquan Zheng, Shengtao Li \\ State Key Laboratory of Electrical Insulation and Power Equipment \\ Xi' an Jiaotong University, Xi'an, Shaanxi, 710049, China \\ and George Chen \\ School of Electronics and Computer Science \\ University of Southampton, Southampton SO17 1BJ, UK
}

\begin{abstract}
Using a computer-aided image recording monitoring system, extensive measurements have been performed in the inner layer of $66 \mathrm{kV}$ cross-linked polyethylene (XLPE) cables. It has been found that there are three kinds of electrical trees in the samples, the branch-like tree, the bush-like tree and the mixed tree that is a mixture of the above two kinds. When the applied voltage frequency is less than or equal to $250 \mathrm{~Hz}$, only the mixed tree appears in XLPE samples, when the frequency is greater than or equal to $500 \mathrm{~Hz}$, only the dense branch-like tree develops, both of which are attributed to the coexistence of non-uniform crystallization and internal residual stress in semicrystalline XLPE cables during the process of manufacturing. Through the fractal analyses of these electrical trees, it has been found that both the propagation and structure characteristics can be described by fractal dimension directly or indirectly. It is suggested that the propagation and structural characteristics of electrical trees are closely related to the morphology and the residual stress in material at low frequency, i.e., the propagation characteristics of electrical trees depends upon not only the boundaries between big spherulites and amorphous region, but also the impurity, micropore concentration and the relative position of needle electrode tip with respect to spherulites or amorphous region in the low frequency range. However, at high frequency, it has nothing to do with the morphology of material. It is suggested that the injection and extraction process of charge from and to dielectrics via the needle electrode are more intense at high frequency than in low frequency. Thus, it can form relatively uniform dielectric weak region in front of needle electrode, which leads to similar initiation and propagation characteristics of electrical trees at high frequency.

Index Terms - Cross-linked polyethylene cable insulation, electrical trees, frequency, residual stress, morphology.
\end{abstract}

\section{INTRODUCTION}

ELECTRICAL treeing is not only the main factor affecting the reliability of cross-linked polyethylene (XLPE) cable insulation, but also the final destructive form

Manuscript received on 15 May 2009, in final form 12 October 2009. of cable insulation operating in the long run. The electrical trees can be initiated from various defects in cable insulation, such as impurity or local high electric field due to the protuberance of semi-conducting shielded layer. It is found that the factors responsible for initiating and propagating of electrical trees in polyolefin cable insulation depend upon not only the cable manufacturing technique, 
the frequency of applying voltage, but also the impurity content, the internal residual stress and physical morphology of insulation material [1-8]. With the increasing applications of $220 \mathrm{kV}$ and above, the insulation of XLPE cables becomes thicker and the harmonic problems in power system could not be neglected in recent years. Considering the high frequency harmonic voltage component in power system, non-uniform crystallization due to thicker extrusion insulation, and the enhancing effect of residual stress on electrical trees, it is now a new challenge to the reliability of cables in operation. It therefore brings up a new subject to the study of electrical trees. Many papers have studied the effects of morphology of semi-crystalline material on the initiation and propagation of electrical trees in the past decades $[5,6,9$, 10], but little attention was paid to the influence of frequency and residual stress on electrical tree in XLPE cable insulation, only the papers concerning the effect of frequency up to $800 \mathrm{~Hz}$ have been reported [7, 11]. In this paper, the initiation, propagation and the structural characteristics of electrical trees under sinusoidal wave high voltage of 50-2000 Hz in XLPE cable insulation are studied systematically. The structural features of electrical trees and the relationship among the structural features, the morphology and residual stress of material in XLPE cable insulation samples are summarized. It is found that the electrical trees propagating in the inner layer of XLPE cable insulation can be divided into three kinds, whose propagation mechanisms are discussed respectively.

\section{SAMPLE PREPARATION AND EXPERIMENTAL SET-UP}

\subsection{SAMPLE PREPARATION}

The samples were taken from a commercial $66 \mathrm{kV}$ high voltage XLPE cable that has not been put into use. The cross-linking byproducts have not been removed before experiments. The cable insulation was cut into hollow disc with a thickness of $5 \mathrm{~mm}$ (shown in Figure 1). The electrode is a typical of point-plane geometry, and two kinds of metal needle electrodes were used, one of which is stainless steel with tip curvature radius of $5 \pm 1 \mu \mathrm{m}$ and the other is made of tungsten with tip curvature radius of $3 \pm 1$ $\mu \mathrm{m}$. In order to keep a good contact between needle electrode and XLPE material, the needle electrode was coated with a very thin layer of polyethylene before being inserted into the sample.

PE coating with a thickness of about $20 \mu \mathrm{m}$ was obtained by dipping the needle electrode into xylene saturated solution of PE followed by taking the needle out to dry. Special purpose built mould was used to heat the samples. The main part of the special mould is a hollow cylinder made of stainless steel with an inner diameter of $60+0.2$ $\mathrm{mm}$, a wall thickness of $10 \mathrm{~mm}$ and a length of $120 \mathrm{~mm}$ which is based on the size of the experimental samples used in the present study. Two flat heat sources which can be attached to the mould were located at both ends of the sample. The needle electrode was inserted into the sample after the mould was heated to $130{ }^{\circ} \mathrm{C}$. A gauge was used to control the depth of the needle insertion. In the present study the needle tip was kept $3 \mathrm{~mm}$ away from the ground electrode. Finally the sample with the inserted needle was cooled down either naturally or by fan. The semiconducting layer was not removed during the processing and used as the ground electrode so that the sample can have a good contact with the ground electrode. For translucent XLPE samples, the surface smoothness plays a very important role in obtaining high quality photos.

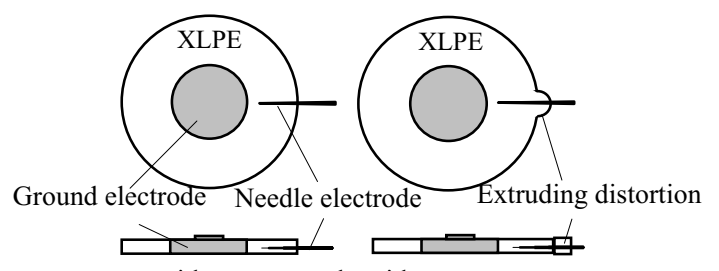

a without stress b with stress

Figure 1. Samples and metal needle electrode.

In order to produce residual stress in the samples, a mechanical pressure was applied to the samples while heating. After the needle was inserted into the sample, the mould was cooled by blowing cool wind. It has been found that the residual stress was not present generally when the needle electrode was inserted into the softened sample followed by a natural cooling. However, the residual stress can be produced if the mechanical pressure was applied during the needle insertion followed by rapid cooling. The first sign of the residual stress presence in a sample is typically indicated by an extruded distortion at the edge of samples (Figure 1b). The residual stress can be further identified by polarization microscope. If the residual stress exists, a color stress diffractive ripple can be observed between two electrodes.

\subsection{SUBMISSION PROCEDURE}

Figure 2 shows the experiment equipment system for the electrical treeing test. The main equipment is a wide band high voltage generator, which consists of a function signal generator and a wide frequency high voltage amplifier (the amplifier gain is 2000 , frequency range is $0-3500 \mathrm{~Hz}$ and the peak-peak value of maximum output voltage is $20 \mathrm{kV}$ ), a microscope with a CCD camera and a computer system. The cable sample was put into a transparent glass container filled with silicone oil and connected to the electrodes. The sample was fully immersed into the silicone oil which is used to strengthen surface insulation of the sample and to eliminate the light scattering caused by uneven sample surface. The images and growth data of the electrical tree were observed and recorded regularly when the selected frequency sinusoidal voltage with a peak value of $10 \mathrm{kV}$ was applied on the needle electrode.

In this paper, the fractal dimension of all electrical trees has been estimated by 2-D projected patterns, the fractal dimension calculating method used is so called boxcounting method $[12,13]$. 


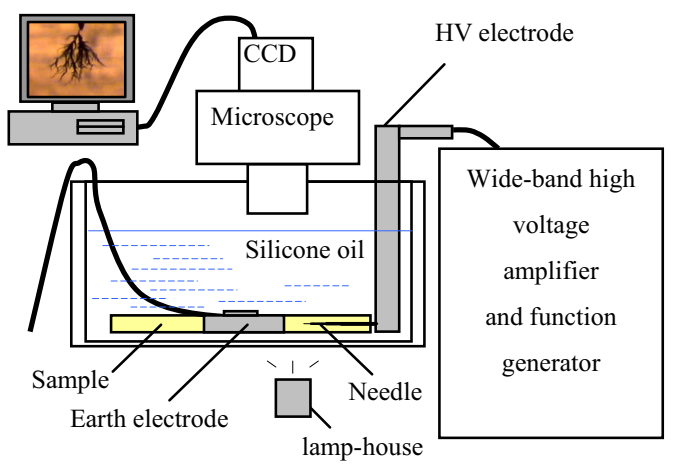

Figure 2. Block diagram of experimental setup for electrical treeing test.

\section{EXPERIMENTAL RESULTS}

In the experiment, all photos of electrical trees are taken at room temperature. The initiation and propagation characteristics of electrical trees in XLPE cable insulation samples under high voltage with a frequency range from 50 to $2000 \mathrm{~Hz}$ are studied. More than 50 electrical trees have been obtained, and more than 400 pictures have been taken. 20 dense branch-like trees electrical trees were gotten at low frequency without residual stress. 12 electrical trees were gotten at low frequency in the presence of residual stress and they belong to so called two-part structure [14]. 20 electrical trees were gotten at high frequency, which are all dense branch-like trees. The experimental results show a very good reproducibility and regularity. It is found that there is remarkable difference in the inception time for different types of electrical trees and it is statistic in nature. The inception voltage is not part of the present study as a fixed voltage was used.

The experiment results according to the frequency of applied voltage and the residual stress are represented as follows.

\subsection{ELECTRICAL TREES IN XLPE CABLE SAMPLES AT LOW FREQUENCY}

\subsubsection{ELECTRICAL TREES IN SAMPLES FREE OF RESIDUAL STRESS AT LOW FREQUENCY}

It is found that three kinds of electrical trees will appear at low frequency $(\leq 250 \mathrm{~Hz})$ under the same sample preparation processes and experiment conditions but different frequency. As shown in Figure 3, there are three kinds of electrical trees: pure sparse branch-like tree (Figure 3a), branch-bush mixed tree, (Figure 3b) [14] and pure bush-like tree (Figure 3c), accounting for $55.6 \%, 33.3 \%$ and $11.1 \%$ respectively of the total number of electrical trees at low frequency. The relation between growth rates and fractal dimensions with growth time of these trees are shown in Figure 4. It is clear that, the growth rate of pure sparse branch-like trees is the fastest, while the bush tree is the slowest. On the basis of fractal analyses [12], it is found that the trees in XLPE cable insulation can be classified as follows: for the electrical tree with fractal dimension $D_{\mathrm{f}} \leq 1.45$, it is pure sparse branch-like; and for the tree with $D_{\mathrm{f}} \geq 1.65$, it is pure bush-like, and if $D_{\mathrm{f}}$ is in the range of $1.45-1.65$, it is dense branch-like or mixed-like. Furthermore, the fractal dimensions of all the three-kind trees increase with growth time, and ultimately reach to a relative constant value (as shown in Figure 4). (Note: $D_{\mathrm{f}}$ data in Figure $4 \mathrm{e}$ are not available for the first 30 minutes because the images for this period were not be recorded.)

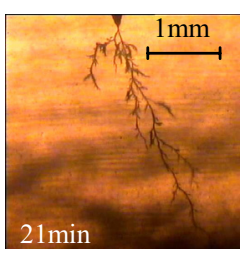

a branch trees Figure 3.

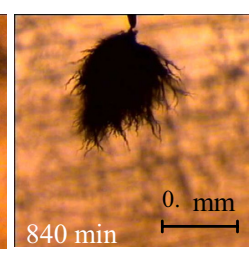

c bush trees

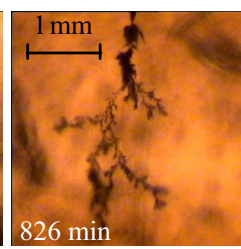

b mixed trees

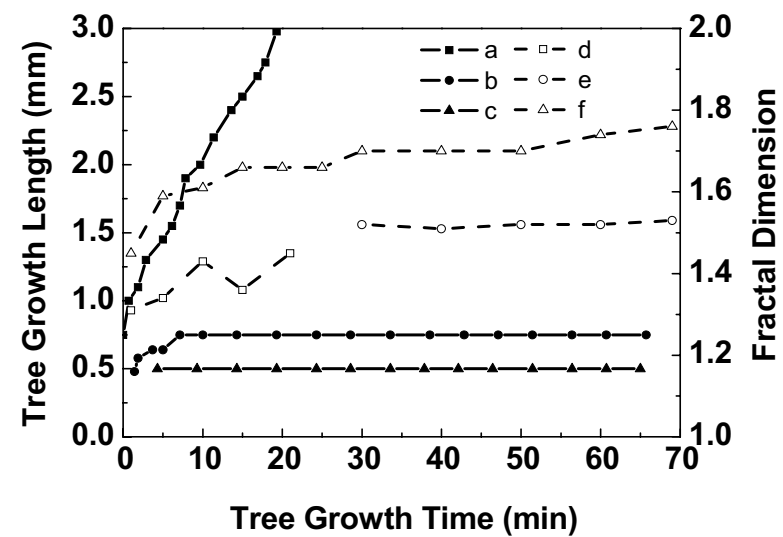

Figure 4. The propagation characteristics of electrical trees at 50 Hz. a, b, c represent the growth rate of the trees in Figures 3a, 3b and $3 \mathrm{c}$, respectively; $\mathrm{d}$, e, f represent the fractal dimension of the trees in Figures 3a, 3b and 3c, respectively.

On the other hand, it is shown that besides the distinct difference in structure, there is a remarkable color difference for the three kinds (Figure 3 ). The color of pure sparse branch-like trees is light gray, the pure bush-like tree has a color of dark black, and the mixed tree is with light gray in branch part and dark black in bush part which indicates that there is large difference in corrosion degree of treeing channels. The black channel of the tree means there is heavy carbon deposited in the channel because the material was corroded by partial discharge (PD). For the gray tree channel it means there is less carbon deposition in the wall of the tree channels. So, one can generally judge conducting characteristics of electrical tree channels by the color of the tree [14]. Therefore, the growth mechanism of these trees should be different. In addition, no stress diffractive ripples are found in the sample by polarization microscope, which indicates that there is no residual stress presence in the samples.

\subsubsection{ELECTRICAL TREES IN THE SAMPLES WITH RESIDUAL STRESS AT LOW FREQUENCY}

Generated at low frequency $(<250 \mathrm{~Hz})$, the electrical trees in samples with residual stress are shown in Figure $5 \mathrm{a}, \mathrm{b}$ and $\mathrm{c}$. The electrical tree 
developed in this situation is usually with a dense branch-like structure within a small region at the beginning and later extending into a pine-branch like or vine-branch-like structure within a larger area, termed as "two-part structure" [14]. For two-part structure trees, the growth rate of the first part is much slower than that of the second; for the second part, the rate of vine-branch-like is faster than that of pine-branch-like [14]. Moreover, the statistical initiation time of electrical trees with residual stress is shorter than the sample without residual stress; the statistical propagation rate of electrical trees with residual stress is faster than that of most samples without residual stress [15].

The relation between growth rates and fractal dimensions with growth time of the three different twopart structure trees in Figure 5 are shown in Figure 6. As shown in Figure 6, the fractal dimensions of the trees shown in Figure $5 \mathrm{a}$ and $5 \mathrm{~b}$ increase with respect to growth time, ultimately tend to a relatively constant value (Figure 5a: $D_{\mathrm{fa}}=1.6,5 \mathrm{~b}: D_{\mathrm{fb}}=1.67$ ), but the fractal dimension of the tree shown in Figure $5 \mathrm{c}$ decreases with respect to growth time (Figure $5 \mathrm{c}: D_{\mathrm{fc}}=$ 1.46). At the same time, it is easy to find that vinebranch-like trees are very light in color (Figure 5c), but the color of pine-branch-like trees are relatively dark (Figures 5a and 5b), which indicates that the propagation mechanisms of the two kind of electrical trees are different from each other.

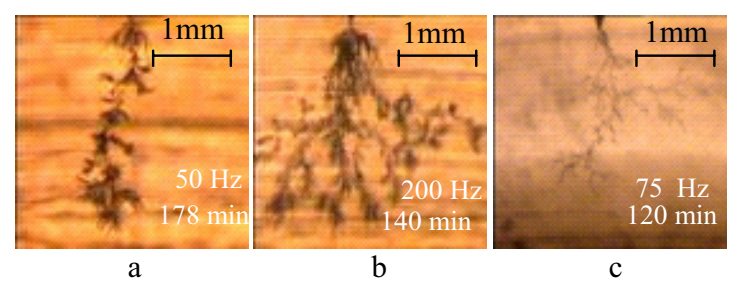

Figure 5. Residual stress trees at low frequency.

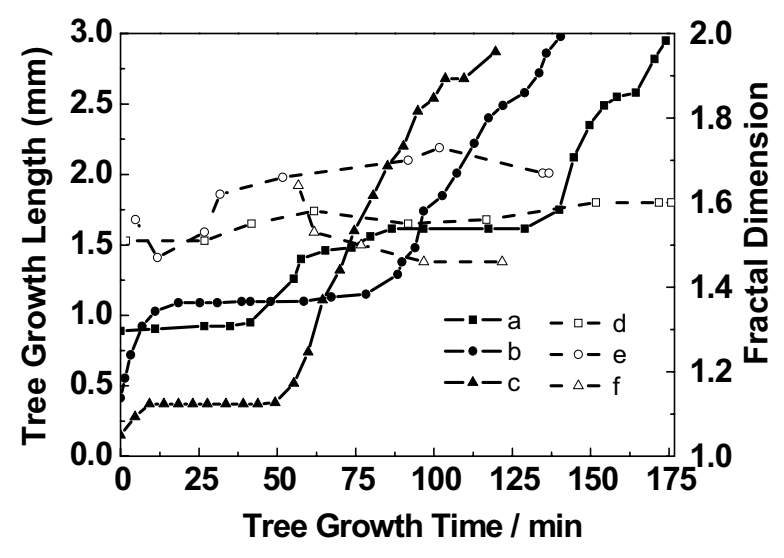

Figure 6. The propagation characteristics of low frequency electrical trees in sample with stress. a, b, c represent the growth rate of the trees in Figures $5 \mathrm{a}, 5 \mathrm{~b}$ and $5 \mathrm{c}$, respectively; $\mathrm{d}$, e, $\mathrm{f}$ represent the fractal dimension of the trees in Figures $5 \mathrm{a}, 5 \mathrm{~b}$ and $5 \mathrm{c}$, respectively.

\subsection{ELECTRICAL TREES IN XLPE SAMPLES AT HIGH FREQUENCY}

The electrical trees generated in samples without residual stress at a frequency of $1 \mathrm{kHz}$ are shown in Figure $7 \mathrm{a}, 7 \mathrm{~b}$ and $7 \mathrm{c}$. It is obvious that only dense branch-like trees appear. The growth length and the fractal dimensions of these three electrical trees with respect to growth time are shown in Figure 8. On the basis of the fractal analyses, it is found that the fractal dimensions of the three electrical trees increase with growth time in the beginning, and then reach to a relatively constant value of 1.52 , which indicates that the structure of these electrical trees nearly keep unchanged in the last period of the tree growth. Furthermore, it can be seen from the color of the electrical trees, the growth rate of the light gray trees are larger than that of the black trees, which is similar to that of at low frequency. Although not presented here, the structure of the electrical trees in the sample with residual stress is very similar to that free of residual stress, the growth rate of the former is larger than that of the latter.

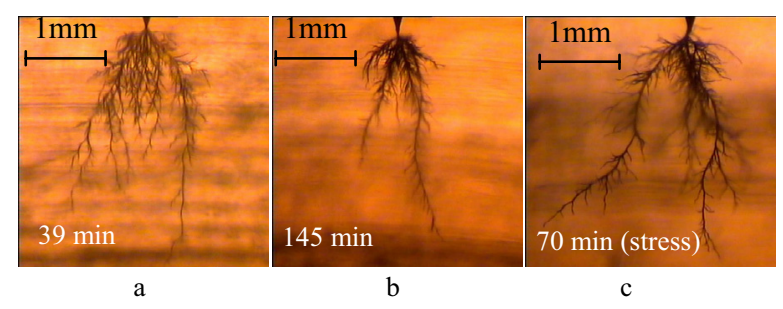

Figure 7. Electrical trees at frequency of $1000 \mathrm{~Hz}$ [15].

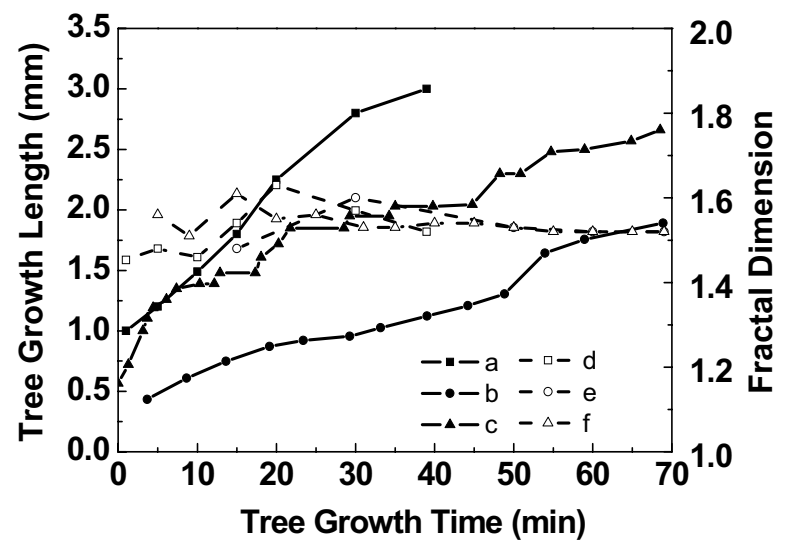

Figure 8. The propagation characteristics of electrical trees at high frequency. a, b, c represent the growth rate of the trees in Figures $7 \mathrm{a}, 7 \mathrm{~b}$ and $7 \mathrm{c}$, respectively; $\mathrm{d}, \mathrm{e}, \mathrm{f}$ represent the fractal dimension of the trees in Figures 7a, 7b and 7c, respectively.

\subsection{SUMMARY ON CHARACTERISTICS OF ELECTRICAL TREES IN XLPE CABLE INSULATION SAMPLES}

The propagation characteristics of electrical trees in XLPE cable insulation samples can be generalized as below: 


\subsubsection{PROPAGATION CHARACTERISTICS}

With the same experimental temperature and applied voltage, multiple types of electrical trees can be generated at low frequency with various shapes and growth rates, whereas they are similar in shapes and develop rates at higher frequency. The statistical propagation rate of electrical trees at high frequency is faster than that at low frequency. The initiation time of the electrical tree in the sample with residual stress is shorter than that of the tree in the sample free of residual stress, and the propagation rate of the former is faster than that of the latter. The effect of frequency mainly accelerates the propagation rate of electrical trees but has no significant influence on the structural characteristics of dense branch-like at high frequency.

\subsubsection{RESIDUAL STRESS EFFECT}

The effect of the residual stress on the structure of the electrical trees in XLPE cable insulation sample mainly took place in low frequency range $(\leq 250 \mathrm{~Hz})$. The structural characteristics of the electrical trees at high frequency are nearly independent of residual stress. It is also shown in the experiments that the growth direction of electrical tree is guided by the residual stress, and the growth of electrical tree can be accelerated by residual stress generally at low frequency.

\subsubsection{THE STRUCTURAL CHARACTERISTICS OF THE TWO-PART STRUCTURE TREES AT LOW FREQUENCY}

The two-part structure trees are the most significant experimental results obtained in our experiments [14]. As has been said in the paper, at low frequency, although the initial propagation rates of two-part structure trees differ from each other, once the vinebranch-like or the pine-branch-like part is initiated, the tree will propagate very fast, and the transversal propagation rates of vine-branch-like part often exceed the longitudinal propagation rates (respect to the direction of applied voltage). Moreover, some singlelong branches of vine-branch-like trees even propagate in the direction opposite to applied voltage. Another propagation characteristic is that there exists a distinct growth ceasing period between the two part structures.

Figure 9 shows the tree photos with residual stress taken by a digital polarization microscope which are partially enlarged photos, corresponding to the trees shown in Figure 5a, c and Figure 7c, respectively. It can be seen clearly that stress diffractive ripples appeared in the sample, indicating the existence of residual stress. Table 1 gives the effects of both frequency and residual stress on the color and growth time of the electrical trees.

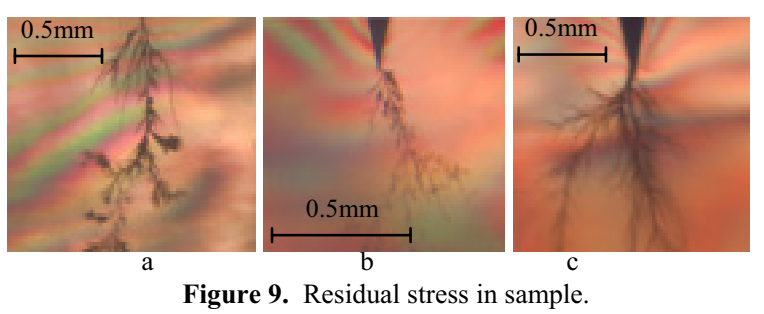

Table 1. The Effects of frequency and residual stress on propagation time and the color of electric trees.

\begin{tabular}{|c|c|c|c|c|c|}
\hline \multirow{2}{*}{$f / \mathrm{Hz}$} & \multirow{2}{*}{50} & \multicolumn{2}{|c|}{ Without stress } & \multicolumn{2}{c|}{ With stress } \\
\cline { 3 - 6 } & $\begin{array}{c}\text { Color } \\
\text { Light } \\
\text { gray } \\
\text { trees }\end{array}$ & $\begin{array}{c}\text { Propagation } \\
\text { time/min }\end{array}$ & $\begin{array}{c}\text { Propagation } \\
\text { length/mm }\end{array}$ & $\begin{array}{c}\text { Propagation } \\
\text { time/min }\end{array}$ & $\begin{array}{c}\text { Propagation } \\
\text { length/mm }\end{array}$ \\
\cline { 2 - 6 } & $\begin{array}{c}\text { Black } \\
\text { trees }\end{array}$ & 826 & 3.0 & & \\
\hline \multirow{3}{*}{1000} & $\begin{array}{c}\text { Light } \\
\text { gray } \\
\text { trees }\end{array}$ & 39 & 3.0 & 178 & 3.0 \\
\cline { 2 - 6 } & $\begin{array}{c}\text { Black } \\
\text { trees }\end{array}$ & 145 & 2.7 & 70 & 2.8 \\
\hline
\end{tabular}

\section{DISCUSSION}

Based on proposed initiation and propagation mechanisms of electrical trees $[10,16-22]$ and the experimental results in this paper, it is suggested that similar initiation mechanisms exist among all of the trees in our experiments $[14,15,23]$. The initiating processes of electrical tree in the inner layer of $66 \mathrm{kV}$ XLPE cable are: electron injection and extraction at the needle electrode due to high electric field, part of the insulation in the front of needle will be deteriorated by this process, this is followed by the intense partial discharge and photo-ionization due to charge recombination in the channel of the tree, the continuous micro-breakdown at the tree tips and the electron avalanche mechanisms, etc.

\subsection{THE ELECTRICAL TREES AT LOW FREQUENCY AND THE NON-UNIFORM CRYSTALLIZATION OF MATERIAL}

The shape and growth characteristics of electrical tree after the initiation mainly depend on the relative position of the needle electrode among spherulites and amorphous part in the sample under the same conditions including constant voltage, constant frequency, etc. Three kinds of electrical trees with different shapes and growth characteristics have been obtained in the similar samples at low frequency (as shown in Figure 3). It is found that the dominant factor leading to the experimental phenomenon is the relative position between the big spherulites and the needlepoint in the inner layer of thick XLPE cable insulation. It can be analyzed as follows: (1) when the tip of the needle electrode just lies in the gap of big spherulites, the initiating process of the tree will be quick because micro-pores and impurities concentrated in the boundary between big spherulites and amorphous region, this boundary insulation disfigurement formed a reticular insulation weak region in 
XLPE samples. The sparse branch-like tree develops rapidly along the direction of this insulation weak region (see Figure 10a), this kind of tree channel wall is often in the state of insulation; (2) Once the initiated branch-like trees penetrate into the big spherulites, because the spherulites has a character of brittle with perfect and pure structure, the growth speed of the tree will reduce greatly or even stop growth over a very long period. The color of the tree inside spherulites will change into dark black and the structure will change into bush-like gradually. The original insulating trees gradually change into conducting tree by weak partial discharge and partial high temperature decomposition of the material in the channel of the tree. The main growth mechanism of the tree also gradually changes from the tree initiation process into tiny breakdown in the tip of the tree. The screen effect by space charge surrounding the spherulites certainly makes the tree nearly cease to grow. Once the tree penetrates out of the spherulites, the new branches will develop along the direction of concentrated insulation defects with a fast growth speed. That is the growth mechanism of branchbush mixed tree (shown in Figure 10b); (3) If the needlepoint of electrode just penetrate into the big spherulites, the process of trees growth inside the big spherulites is similar to the process of (2) as discussed above, the tree channel will have a character of conducting and the tree will propagate with a way of tiny breakdown at the tip of the tree, this can be proved by the black color of the treeing process. For the reason of the experimental result of the treeing with a very long stop period, that is because the injected space charge from the tip of the conducting electrical trees to the dielectric will symmetrically distribute in charge traps on the surface of the spherulites, the screen effect by space charge surrounding the spherulites makes the tree in spherulites cease for propagation (shown in Figure 10c). To verify this, we can do the following calculation.

Using the real size of electrical trees in experiments (as shown in Figure 3c) and presuming that the radius of uniform distributed space charge screening shell is $r_{1}=0.5 \mathrm{~mm}$ and the distance between the tips of electrical trees and ground electrode is $r_{2}=2.5 \mathrm{~mm}$ (assume the length of electrical tree is $0.5 \mathrm{~mm}$ ), and the applied voltage is $U=7 \mathrm{kV}$, then the real electrical field can be estimated as follows:

$$
E=U /\left(r_{1}-\left(r_{1}^{2} / r_{2}\right)\right) \approx 17.5 \mathrm{MVm}^{-1}
$$

which indicates that the field at tips of electrical trees surrounded by the space charges is less than the breakdown strength of polyethylene $\left(E<E_{b}\right.$ and $E_{b}=18-28 \mathrm{MVm}^{-1}$ [2]), so the space charge screening shell indeed inhibits the growth of electrical trees.

From the polarization photos and SEM (Scanning Electron Microscop), it is evident that the big spherulites exist among vine-branch-like trees (Figure 11) and there is a large morphology difference (Figure 12) between the inner and outside layer of the sample clearly. The observing cross-section of the samples was obtained by brittle rupturing the sample placed inside liquid nitrogen at the temperature of $-190{ }^{\circ} \mathrm{C}$, then sprayed gold electrodes, and then the morphology of cross-section of the samples was obtained with the SEM. It is fond that the size of the spherulites is generally among $1-10 \mu \mathrm{m}$. As it is showed in literature [24, 25], the resistance to electrical trees in XLPE cable insulation is worse than PE because of the imperfect crystallization and the formation of large spherulites of XLPE due to crystal nucleus destroyed by cross linking. Literature [26] has studied the crystalline morphology of the $35 \mathrm{kV}$ XLPE cable insulation by Freeze-rupture and potassium permanganate etching method and found that the diameters of the equivalent spherulites in the cable insulation were typically between $4-40 \mu \mathrm{m}$ or greater.

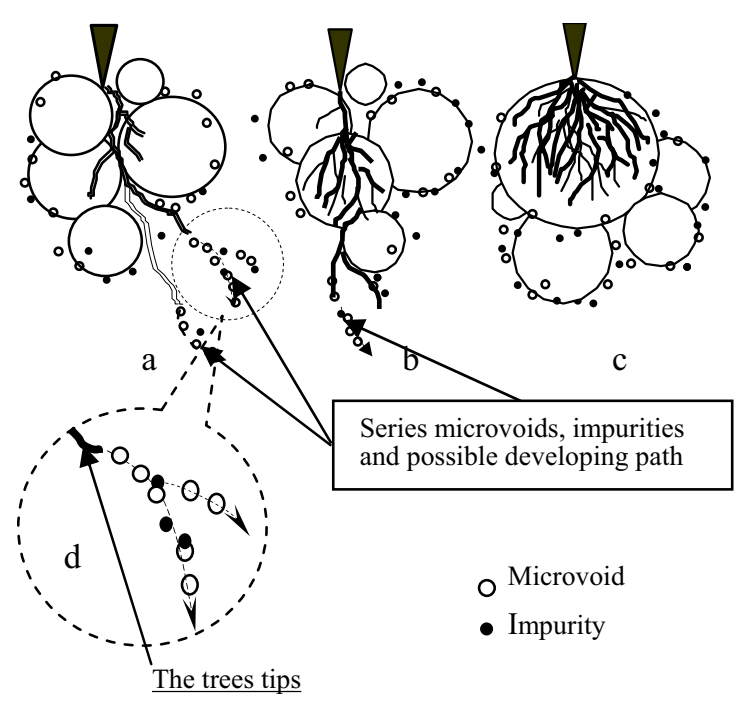

Figure10. The effects of spherulites on the trees in low frequency. a, The needlepoint is in the gap of spherulites; $b$, Branch-like tree penetrate into the spherulites; $c$, The needle point just penetrate into the big spherulite; d, The possible developing path of trees along the series microholes and the concentration of impurity.

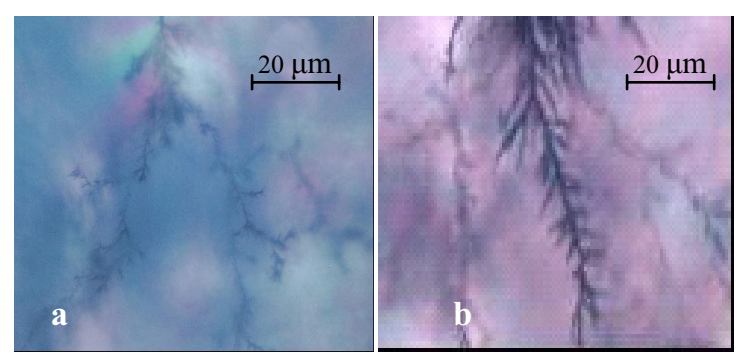

Figure11. The big spherulites in samples.

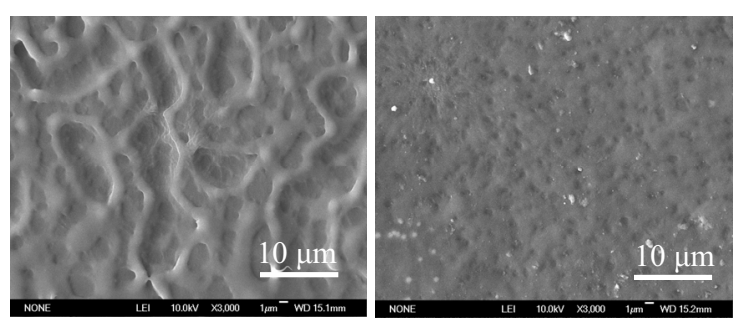

(a) Inner layer

(b) Out layer

Figure 12. The morphology difference in the sample. 


\subsection{THE ELECTRICAL TREES WITH RESIDUAL STRESS AT LOW FREQUENCY}

The electrical trees generated with residual stress at low frequency sinusoidal wave voltage usually have the twopart structure. Once the second part of two-part structure trees was formed, the electrical trees will propagate with a faster rate in a broader area. There are two reasons for the appearance of pine-branch tree, one is the tiny breakdown of the material at the tip of needle, which is proved by the black color of the tree implying the conducting tunnel of the tree; the other reason is that the residual stress makes the material in this region more easily to break down. In addition, the growth characteristics of two-part structure trees generated under residual stress are similar to those generated trees after PD [27].

As Zhao et al found [4] that when linear PE is crystallized at the temperature of $115{ }^{\circ} \mathrm{C}$, spherulites are formed closely together. The trees will grow around spherulites or along intergranular layer between the spherulites in this case. In addition, at $120{ }^{\circ} \mathrm{C}$ the polyethylene copolymer can be crystallized to form separate spherulites with high concentration. In this kind of material, the propagation process of the electrical trees cannot be considered to be stochastic. For instance, when the material is crystallized at $124{ }^{\circ} \mathrm{C}$, it is observed that 12 percent of electric trees are located at the surface layer of the spherulites, 20 percent occurs in the region with low crystalline and $68 \%$ are related to the boundary of the spherulites. As it is showed in literature [24, 25] that the electrical trees of XLPE cable insulation were easier for growth along the large spherulites surface because of the imperfect crystallization and the existence of large spherulites in XLPE. As pointed out by Toshikatsu Tanaka [10], the weak region is composed of the delamination and three-dimensional network among spherulites. It has proved that the tree channels are related to these weak networks.

On the basis of the analyses in this paper, it is proposed that the continual weak region can be formed in the amorphous region among the spherulites because of both the delaminating phenomena of the spherulites and the tension or compression of the residual stress. The electrical trees will grow in a way of tiny breakdown along this weak region, when space charges have been injected into the area and led to partial electric field distortion before electrical tree initiating. According to the thermal distortion of samples during its processing, such a delaminating of the spherulites in XLPE cable insulation is more likely to be perpendicular to the direction of the applied field (shown in Figure 13). This can explain our experiment that many vine-branch-like trees develop along the direction nearly perpendicular to the direction of the applied field, and some branches even grow along the direction opposite to the applied field. As showed in Fig. 3b, the reason for the electrical trees grown rapidly in the direction almost perpendicular to the applied electric field is that many defects, such as micro-voids and impurities etc, accumulated along this direction. The driving force for this tree branch development is local high temperature and pressure due to PD in main branch of the tree [28].

The experimental results above can be explained as follows theoretically.

The necessary condition for the extension of tubular cracks is that the sum of both the electrostatic energy $W_{e s}$ and the electric mechanical energy $W_{e m}$ stored in tree channels must be larger than the sum of both the plastic deformation energy $W_{f p}$ and the surface energy $W_{f s}$, their

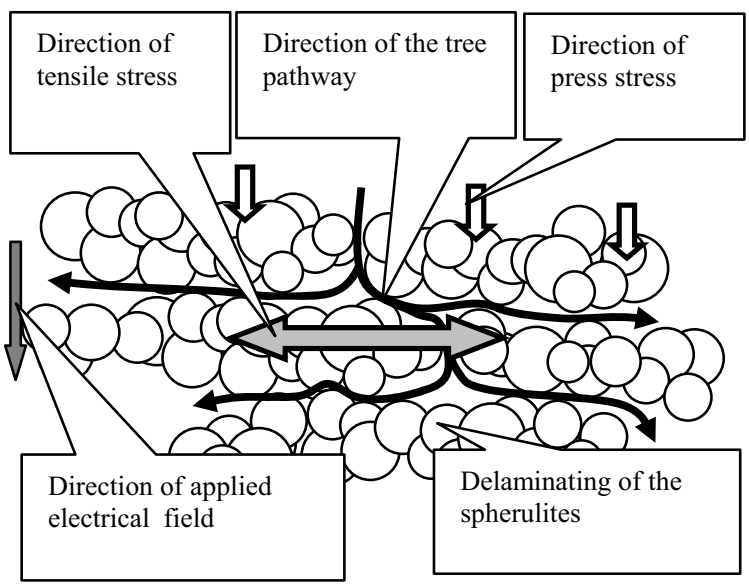

Figure 13. Diagram of the delaminating of spherulites and stress in sample.

values can be approximately given by the following equations [16]

$$
\begin{aligned}
& W_{f p}=\pi r^{2} L \alpha \sigma_{y} \\
& W_{f s}=2 \pi r L \gamma
\end{aligned}
$$

where $\gamma$ is the surface tension, $\alpha$ is a correction factor, $\sigma_{y}$ is the yield stress, and $L$ and $r$ are the length and radius of the cylindrical cavity of the electrical trees, respectively.

If a static stress exists in the material, $W_{f p}$ will reduce to $W_{f p}^{\prime}$, namely,

$$
W_{f p}^{\prime}=W_{f p}-\frac{\sigma e \pi r^{2} L}{2}
$$

In equation (3), $\sigma$ is the residual stress and $e$ is the tension level. Equation (3) indicates that the residual stress leads to the decrease of the plastic deformation energy $W_{f p}$ of the material along the stress extension direction, so the electrical trees growth along the direction of stress extension.

\subsection{THE ELECTRICAL TREES AT HIGH FREQUENCY}

Due to the intense PD at high frequency, electrical tree growth is less affected by the material morphology and residual stress. PD is the main reason for the electrical tree growth at high frequency. At high frequency the combined effects of local high temperature and partial pressure produced by intense PD and channels decomposition always make the initial branch-like trees continue to grow until they reach the opposite electrode, and the existence of 
space charge will promote this process [29]. So electrical trees initiated at high frequency mostly have a dense branch-like structure; but the growth rate of the tree in the presence of residual stress at high frequency will be faster than those without residual stress, which indicates that weak link chain resulting from the presence of residual stress is more easily broken and PD is more intense in the branch channel.

\subsection{THE CRYSTALLIZATION AND THE RESIDUAL STRESS}

After analyzing the characteristics of growth speed and structure of the vine-branch tree reported in recent years, it is found that this kind of electrical tree must be the result of residual stress cooperated with morphology in XLPE cable insulation.

The significance of the research in this paper is that, considering the influence of morphology and residual stress to electrical aging of XLPE cable insulation, much attention should be paid to the cooling temperature and cooling rate during the cable manufacturing. It is also very important to use appropriate post-treatment for XLPE cable insulation so as to get reasonable morphology and to eliminate the residual stress in cable insulation. Furthermore, using super-clean XLPE-cable producing technique to eliminate the defects between crystalline and amorphous region, this may be one of the most important methods to improve the character of treeing resistance of XLPE cable insulation. Recently, we have found the proof that higher voltage rating XLPE cables have a much better treeing resistance characteristic than $66 \mathrm{kV}$ or below XLPE cables, and there is very significant difference in morphology and impurity content between the two materials. Of course, eliminating and reducing harmonic wave in Power Grids are practical significance to the safety of XLPE cable insulation.

\section{CONCLUSIONS}

a) The initiation mechanism of different structure of electrical trees in XLPE cable insulation is similar. The propagation mechanism of electrical trees at high frequency $(f \geq 500 \mathrm{~Hz})$ is also similar, i.e. electron injects into and extracts from sample via electrode, the violent partial discharge in the channel of the trees, photo-ionization by charge recombine in the tree channel, the tiny-breakdown in the polymer around tree tips and the electron avalanche mechanisms, etc.

b) On the basis of fractal analyses, the electric trees can be approximately classified into three kinds. If the fractal dimension $D_{\mathrm{f}} \leq 1.45$, the trees would be branch-like; if 1.45 $\leq D_{\mathrm{f}} \leq 1.65$, they will be dense branch- or mixed-like; if $D_{\mathrm{f}}$ $>1.65$, they will be bush-like. If the $D_{\mathrm{f}}$ remains almost unchanged during the treeing process, the trees would grow at almost a constant rate, and the structure of the trees also remains unchanged. If the $D_{\mathrm{f}}$ decreases with time, the tree growth process will speed up, and the structure of the tree will become sparse. If the $D_{\mathrm{f}}$ increases with time, the growth speed will decrease, and the structure of tree will become dense. c) It has been found that at low frequency and no residual stress conditions, there are branch-like trees, mixed trees with branch-and bush-like together and pure bush-like trees in XLPE cable insulation. The structures of three electric trees depend upon the relative position between needlepoint and spherulites.

d) For the samples with residual stress and at low frequency, the structure of electrical trees will be two-part structure-like, and first part will have a structure of dense branch-like within a small region and second will have a structure of pine-branch like or vine-branch-like within a larger area. As for the growing rate, the latter is much faster than the former. There are two reasons for black color pinebranch tree appeared, one is the tiny breakdown of the material in the tip of needle, and PD is very weak in the channel of the treeing in this situation; the other reason is the residual stress that makes the material in this region more easily be breakdown, and the influence for treeing is lager than morphology in this situation.

e) For the electrical trees initiated and grown at high frequencies, the trees are always dense-branch-like due to intense partial discharge inside the channel regardless of the residual stress. Their growth characteristics and structures have nothing to do with spherulites. The residual stress will accelerate the growth rate but never change structures of the trees.

f) The residual stress only affects the structure of electrical trees at low frequency, while it has no effect at high frequency.

\section{ACKNOWLEDGMENT}

The authors wish to thank the National Science Fund for Outstanding Young Scholars of China under Projects No.50625721 and the National Science Foundation of China under Projects No.50577052.

\section{REFERENCES}

[1] J. V. Champion, S. J. Dodd, Y. Zhao, A. S. Vaughan, M. Brown, A. E. Davies, S. J. Sutton and S. G. Swingler, "Morphology and Growth of Electrical Trees in a Propylene/ethylene Copolymer", IEEE Trans. Dielectr. Electr. Insul., Vol. 8, pp. 284-292, 2001.

[2] J. V. Champion, S. J. Dodd, A. S. Vaughan, Y. Zhao, and S. J. Sutton, "Effect of Voltage, Temperature and Morphology on Electrical Treeing in Polyethylene Blends", Proceedings of Dielectric Materials, Measurement and Applications, London Guildhall Univ., UK, IEE Conf. Publication, No.473, pp. 35-40, 2000.

[3] E. David, J. Parpal, and J. Crine, "Influence of Internal Mechanical Stress and Strain on Electrical Performance of Polyethylene", IEEE Trans. Dielectr. Electr. Insul., Vol. 3, pp. 248-57, 1996.

[4] Y. Zhao, A. S. Vaughan, J. V. Champion, S. J. Dodd, and S. J. Sutton, "The structure of Electrical Trees in Semi-crystalline Polymers", Proceedings of Dielectric Materials, Measurement and Applications, London Guildhall Univ., UK, IEE Conference Publication, No. 473, pp. 314-319, 2000.

[5] J. V. Champion and S. J. Dodd, "The Effect of Material Composition and Temperature on Electrical Tree Growth Epoxy Resins", Proceedings of Dielectric Materials, Measurement and Applications, London Guildhall Univ., UK, IEE Conf. Publication, No. 473, pp. 314-319, 2000.

[6] L. A. Dissado, "Understanding Electrical Trees in Solid: From Experiment to Theory”, IEEE Trans. Dielectr. Electr. Insul., Vol. 9, pp. 483-497, 2002. 
[7] Suwarno, Y. Suzuoki, T. Mizutani, K. Uchida, "Effects of Frequency and Applied Voltage on Electrical Treeing Discharges", IEEE Intern. Conf. Conduction and Breakdown in Solid Dielectrics, Nagoya Univ., Japan. pp. 366-370, 1995.

[8] L. Cisse, G. Teyssedre, D. Mary, and C. Laurent, "Influence of Frequency, Electrode Material and Superimposed dc on ac Electroluminescence in Polymer Films", IEEE Trans. Dielectr. Electr. Insul., Vol. 9, pp. 124-129, 2002.

[9] Y. X. Zhou, X. G. Luo, P. Yan, X. D. Liang, Z. C. Guan, and N. Yoshimura, "Influence of Morphology on Tree Growth in Polyethylene", Intern. Sympos. Electrical Insulating Materials (ISEIM) Himeji, Japan, pp. 194-197, 2001.

[10] T. Tanaka, "Space Charge Injected Via Interfaces and Tree Initiation in Polymers", IEEE Trans. Dielectr. Electr. Insul., Vol. 8, pp. 733743, 2001.

[11] R. J. Densley, "An Investigation into the Growth of Electrical Trees in XLPE Cable Insulation", IEEE Trans. Dielectr. Electr. Insul., Vol. 3, pp. 148-158, 1979.

[12] K. Kudo, "Fractal Analysis of Electrical Trees", IEEE Trans. Dielectr. Electr. Insul., Vol. 5, pp. 713-727, 1998.

[13] A. L. Barclay, P. J. Sweeney, L. A. Dissado, and G. C. Stevens, "Stochastic Modelling of Electrical Treeing: Fractal and Statistical Characteristics", J. Phys. D: Appl. Phys., Vol. 23, pp. 1536-1545, 1990.

[14] X. Q. Zheng and G. Chen, "Propagation Mechanism of Electrical Tree in XLPE Cable Insulation by Investigating a Double Electrical Tree Structure", IEEE Trans. Dielectr. Electr. Insul., Vol. 15, pp. 800-807, 2008

[15] X. Q. Zheng, G. Chen, and A. E. Davies, "The Influence of Survival Mechanical Stress and Voltage Frequency on Electrical Tree in XLPE”, IEEE Conf. Electr. Insul. Dielectr. Phenomena (CEIDP), pp. 955-958, 2002

[16] M. N. Arbab and D.W. Auckl, "Growth of Electrical Trees in Solid Insulation", IEE Proc. A Sci. Measurement and Technology, Vol. 136, pp. 73-78, 1989.

[17] J. C. Fothergill, "Filamentary Electro-mechanical Breakdown", IEEE Trans. Dielectr. Electr. Insul., Vol. 26, pp. 1124-1129, 1991

[18] J. M. Alison, J. V. Champion, S. J. Dodd, and G. C. Stevens, "Dynamic Bipolar Charge I Recombination Model for Electro Luminescence in Polymer Based Insulation During Electrical Tree Initiation", J. Phys. D: Appl. Phys., Vol. 28, pp. 1693-701, 1995.

[19] M. D. Noskov, M. Sack, A. S. Malinovski, and A. J. Schwab, "Measurement and Simulation of Electrical Tree Growth and Partial Discharge Activity in Epoxy Resin", J. Phys. D: Appl. Phys., Vol. 34 pp.1389-1398, 2001.

[20] K. Wu, Y. Suzuoki, T. Mizutani, and H. K. Xie, "Model for Partial Discharges Associated with Treeing Breakdown: I.PDs in tree channels", J. Phys. D: Appl. Phys., Vol. 33, pp. 1197-1201, 2000.

[21] K. Wu, Y. Suzuoki, T. Mizutani, and H.K. Xie, "Model for Partial Discharges Associated With Treeing Breakdown: II. Tree Growth Affected by PDs", J. Phys. D: Appl. Phys., Vol. 33, pp. 1202-1208, 2000.

[22] I. L. Hosier, S. J. Dodd, S. J. Sutton and A. S. Vaughan, "On the Structure and Chemistry of Electrical Trees in Polyethylene", J. Phys. D: Appl. Phys., Vol. 39, pp. 962-978, 2006.

[23] X. Q. Zheng, A. S. Xie and S. T. Li, "The Electrical Trees That in Inner and Outer Layer of XLPE Cable Insulation", Acta Phys. Sin., Vol. 56, pp. 5494-08, 2007 (in Chinese)

[24] A. Harlin, "Insulation Morphology Effects on the Electrical Treeing Resistance", IEEE Trans. Dielectr. Electr. Insul., Vol. 9, pp. 401-405, 2002.

[25] Y. H. Long, D. R. Xie, N. P. Wu, "The effects of crosslinking degree on morphology and electrical properties of polyethylene", Electric Wire \& Cable, No. 05, pp. 20-23, 1993 (in Chinese).

[26] S. Bamji, A. Bulinski, J. Densley and A. Carton, "Etching and the Morphology of Cross-Linked Polyethylene Cable Insulation", IEEE Trans. Dielectr. Electr. Insul., Vol. 18, pp. 32-415, 1983.

[27] K. Wu, Y. Suzuoki, T. Mizutani, and H.K. Xie, "Model for partial discharges associated with treeing breakdown: III. PD extinction and re-growth of tree", J. Phys. D: Appl. Phys., Vol. 33, pp.1209-1218, 2000 .
[28] Y. T. Wang, X.Q. Zheng, G. Chen and A. E. Davies, "Influence of Polymer Congregating State and Survival Mechanical Stress to Electrical Treeing in XLPE", Trans. China Electrotechnical Soc., Vol. 19, pp. 44-48, 2004 (in Chinese).

[29] M. Mammeric, C. Laurent and J. Salon, "Influence of Space Charge Build up on the Transition to Electrical Treeing in PE Under AC Voltage", IEEE Trans. Dielectr. Electr. Insul., Vol. 2, pp. 27-35, 1995.

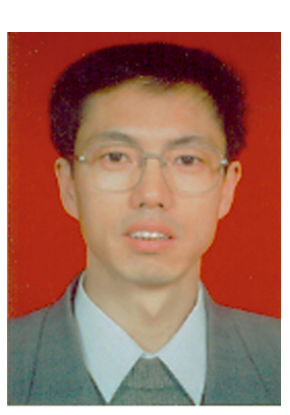

Ansheng Xie was born in 1964 in Shaanxi, China. He received the B.S. degree in electrical engineering from Xi'an Jiaotong University, Xi'an, China, and M.S. degree in thermal measurement and optimal control from Harbin University of Civil Engineering and Architecture, Harbin, China, in 1989 and 1996, respectively. Presently, he is a Doctor student at the Department of Electrical Engineering of Xi'an Jiaotong University. His research interests are in the measuring technology of dielectric materials and electrical treeing in polymers.

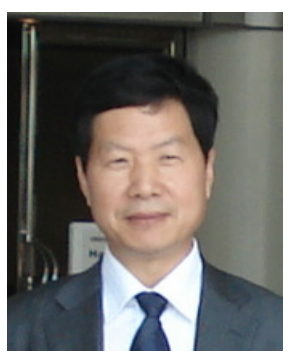

Xiaoquan Zheng, was born in China in 1954. $\mathrm{He}$ received the B.Eng., M.Sc. and Ph.D. degrees in electrical engineering from $\mathrm{Xi}^{\prime}$ an Jiaotong University, China in 1982, 1990, and 2000 , respectively. He was in Southampton University, UK as a Visiting Scholar from 2001 to 2002. He has been a Professor since 2007 in the Department of Electrical Engineering, Xi' an Jiaotong University and is engaged in research and teaching on the properties and measuring technology of dielectric materials and published over 50 papers.

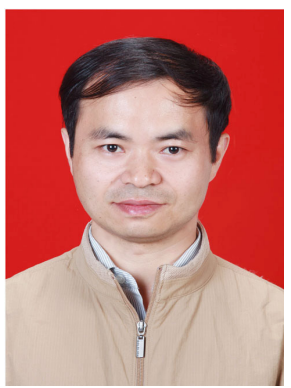

Shengtao Li, (M'96), was born in Sichuan, China, in February, 1963. He received the B.Sc., M. Sc. and Ph.D. degrees in electrical engineering, from Xi' an Jiaotong University in 1983, 1986, and 1990, respectively. Currently, he is a professor at the State Key Laboratory of Electrical Insulation and Power Equipment in Xi'an Jiaotong University. His research interests include electronic ceramics and devices, insulating materials and insulation system, electrical treeing in polymers.

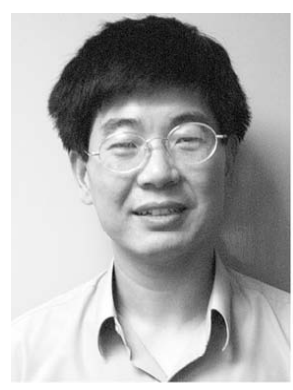

George Chen was born in China in 1961. He received the B.Eng. and M.Sc. degrees in 1983 and 1986, respectively in electrical engineering from Xi'an Jiaotong University, China. After he obtained the Ph.D. degree in 1990 in electrical engineering from The University of Strathclyde, UK, he joined the University of Southampton as a postdoctoral research fellow and became a senior research fellow subsequently. In 1997 he was appointed as a research Lecturer and was promoted to a Reader in 2002. Over the years, he has developed a wide range of interests in high voltage engineering and electrical properties of materials and published over 100 papers. He is a visiting Professor at Xi' an Jiaotong University, China. 